\title{
Flow microreactor synthesis in organo-fluorine chemistry
}

\author{
Hideki Amii ${ }^{*}$, Aiichiro Nagaki ${ }^{2}$ and Jun-ichi Yoshida ${ }^{* 2}$
}

\section{Review}

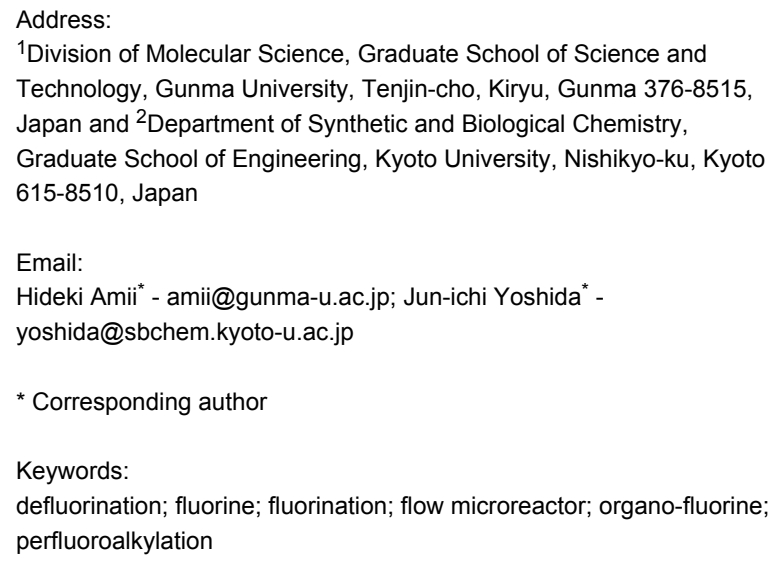

\begin{abstract}
Organo-fluorine compounds are the substances of considerable interest in various industrial fields due to their unique physical and chemical properties. Despite increased demand in wide fields of science, synthesis of fluoro-organic compounds is still often faced with problems such as the difficulties in handling of fluorinating reagents and in controlling of chemical reactions. Recently, flow microreactor synthesis has emerged as a new methodology for producing chemical substances with high efficiency. This review outlines the successful examples of synthesis and reactions of fluorine-containing molecules by the use of flow microreactor systems to overcome long-standing problems in fluorine chemistry.
\end{abstract}

\section{Review}

Fluorine is a key element in the development of materials and biologically active agents. The introduction of fluorine atoms into organic molecules often exerts influences upon physical, chemical, and biological properties [1-8]. Although the fluorine atom is larger than the hydrogen atom, the replacement of hydrogen by fluorine leads to the smallest steric perturbation available to us. In pharmaceuticals, fluorine is often introduced to increase lipophilicity, bioavailability, and metabolic stability; these unique properties are otherwise difficult to obtain. At

present, nearly $15 \%$ of medicines and $20 \%$ of agrochemicals on the market contain fluorine atoms $[6,9,10]$.

Despite increased demands in wide fields of science, synthesis of fluoro-organic compounds is still often faced with problems such as the difficulty in handling of fluorinating reagents and in controlling of chemical reactions. Furthermore, low stability of fluorine-containing intermediates and low selectivity (chemo-, regio-, and/or stereo-) of the reactions have disturbed the 
progress of synthesis of fluorochemicals. New methodologies that can cure the weak points in synthesizing fluoro-organic compounds would open up a new perspective for fluorine chemistry.

Meanwhile, flow microreactor synthesis, the use of microfluidic devices, has emerged as a new method for producing chemical substances with high efficiency [11-13]. Now, the introduction of continuous-flow synthesis technique to laboratory synthesis represents a highly useful and increasingly popular method in organic chemistry [14-17]. Flow microreactor systems serve as an effective method for precise control of chemical reactions. Not only operational safety, but also extremely fast mixing, efficient heat transfer, and precise residence time control by virtue of the characteristic features of microstructures are responsible for their effectiveness. In particular, brilliant works of the generation and reactions of reactive intermediates that cannot be done in batch reactors have been developed by means of 'space integration methodology', where a sequence of reactions is conducted in one flow by adding the reagents at different places in continuous-flow synthesis [18-25].

This review deals with the successful examples on synthesis and reactions of fluorine-containing molecules by the use of flow microreactor systems. Useful applications using flow microreactor technology to overcome long-standing problems in synthetic organofluorine chemistry are showcased.

\section{Reactions using hazardous fluorinating reagents}

Direct fluorination employing elemental fluorine $\left(\mathrm{F}_{2}\right)$ is one of the most straightforward methods to make fluorine-containing molecules with high atom economy. However, handling $F_{2}$ needs special care and there are a lot of practical difficulties associated with direct fluorination. Elemental fluorine is a poisonous pale yellow gas at room temperature $\left(\mathrm{bp}-188^{\circ} \mathrm{C}\right)$. Reactions of organic substances with elemental fluorine are typically strongly exothermic and extremely fast, frequently explosive. So it is difficult to control direct fluorination reactions with $\mathrm{F}_{2}$ gas in conventional batch reactors. In 1999, the pioneering work using flow microreactor technology for direct fluorination was reported by Chambers and Spink (Scheme 1) [26]. Utilizing the flow microreactor system, selective fluorination reactions were accomplished. For instance, fluorination of $\beta$-dicarbonyl compounds proceeds with high efficiency, whereas the use of conventional macrobatch systems suffered from low conversion $[27,28]$. Since then, direct fluorination processes using flow microreactor systems have been studied extensively [29-36]. The reactions of arenes with $F_{2}$ gas cause not only substitution (aromatic fluorination) but also side reac- tions such as fluorine-addition, polymerization and so on due to the high reactivity of $F_{2}$ gas [37-40]. Direct fluorination of aromatics in microreactor system took place cleanly [36].

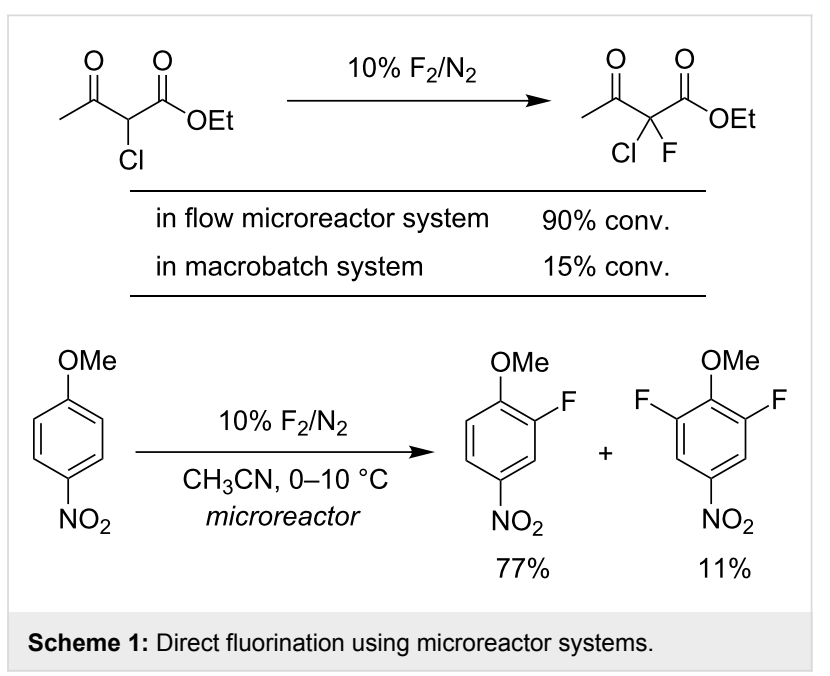

As another splendid example for safe handling of hazardous fluorinating reagents, the flow microreactor synthesis using diethylaminosulfur trifluoride ( $\mathrm{Et}_{2} \mathrm{NSF}_{3}$, abbreviated as DAST) was demonstrated. DAST is a commercially available liquid reagent that is utilized for the conversion of alcohols and carbonyl compounds into the corresponding fluoro derivatives. In spite of the effectiveness and convenience for nucleophilic fluorination, DAST is volatile and quite moisture sensitive, and readily undergoes disproportionation to $\mathrm{SF}_{4}$ and explosive $\left(\mathrm{Et}_{2} \mathrm{~N}\right)_{2} \mathrm{SF}_{2}$ when heating at over $90{ }^{\circ} \mathrm{C}$ [41-43]. Therefore, special care is required in handling a large quantity of DAST concerning the danger of the explosion under heating conditions. To solve these technical issues, the use of DAST in a continuous-flow reactor employing inert plastic flow tubes provided flexibility, scale-up production, and improved safety of operation. Using flow chemistry, the conversion of alcohols to fluorides was achieved by Seeberger and Ley, independently (Scheme 2) [44-47]. Usually, gem-difluorination of ketones by DAST is known to be less efficient because it needs heating and/or long reaction time to complete the fluorination [48,49]. Nevertheless by the use of a flow microreactor device, isatin underwent gem-difluorination to give the corresponding difluoride in $73 \%$ yield (residence time in the reactor: within $1 \mathrm{~h}$ ).

\section{Reactions that can be well-controlled and accelerated using flow microreactor systems}

The success of continuous flow chemistry in organic synthesis has enlarged rapidly last decade. There have been numerous examples using flow microreactors with improvement of chemical conversions and selectivities compared to conventional batch equipments. There are several beneficial effects using of 


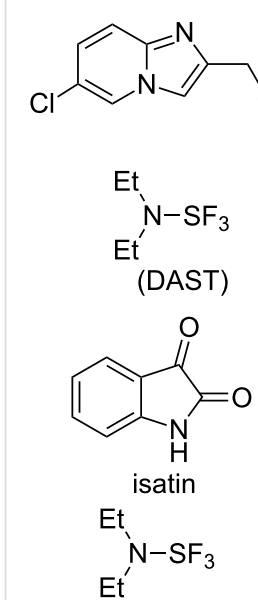

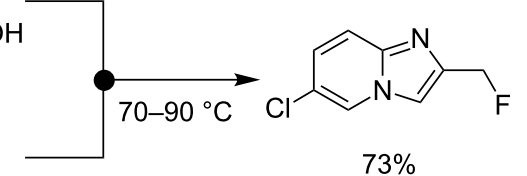

(DAST)

(DAST)
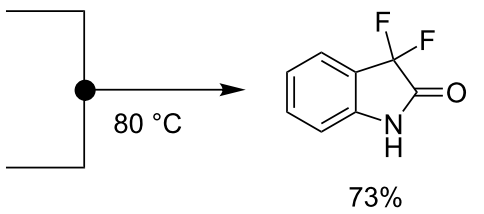

Scheme 2: Use of DAST in continuous-flow reactors.

flow microreactor systems; for instance, extremely fast mixing ability attributed to shortened diffusion path length, and highly efficient heat transfer ability based on large surface-area-to- volume ratio. In some cases, product selectively can be enhanced dramatically by the use of continuous flow microreactor devices. Daikin Industries, Ltd. developed the flow microreactor synthesis of fluorinated epoxides. In the first step (radical addition of perfluoroalkyl iodides to unsaturated alcohols), there is a problem concerning the violent exothermic reaction induced by decomposition of AIBN [50]. Furthermore, in the second step (intramolecular nucleophilic substitution of $\beta$-iodoalcohols to afford epoxides), efficient mixing technique is required for biphasic aqueous-organic systems. To resolve all the troublesome issues, flow microreactor provided improved reaction control over traditional batch reactors; high-yield synthesis of fluorinated epoxides was achieved (Scheme 3).

Kitazume et al. demonstrated the benefit of flow microreactors for a highly stereoselective synthesis of difluoromethylated alkenes [51]. They succeeded in perfect control of rapid basecatalyzed isomerization to give (E)-ethyl 3-difluoromethylpropenates (Scheme 4). Due to the benefit of temperature control in flow microreactor, further isomerization affording $\mathbf{B}$ was restricted.
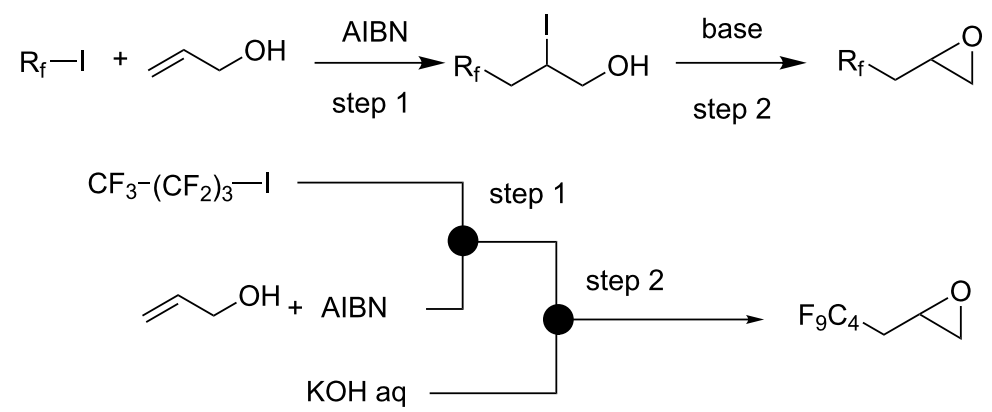

\begin{tabular}{lll} 
& \multicolumn{1}{c}{ step 1 } & \multicolumn{1}{c}{ step 2 } \\
\hline in flow microreactor system & 20 min, 97\% yield & 17 min, 97\% yield \\
in macrobatch system & $8 \mathrm{~h}, 97 \%$ yield & $2 \mathrm{~h}, 84 \%$ yield \\
\hline
\end{tabular}

Scheme 3: Flow microreactor synthesis of fluorinated epoxides.

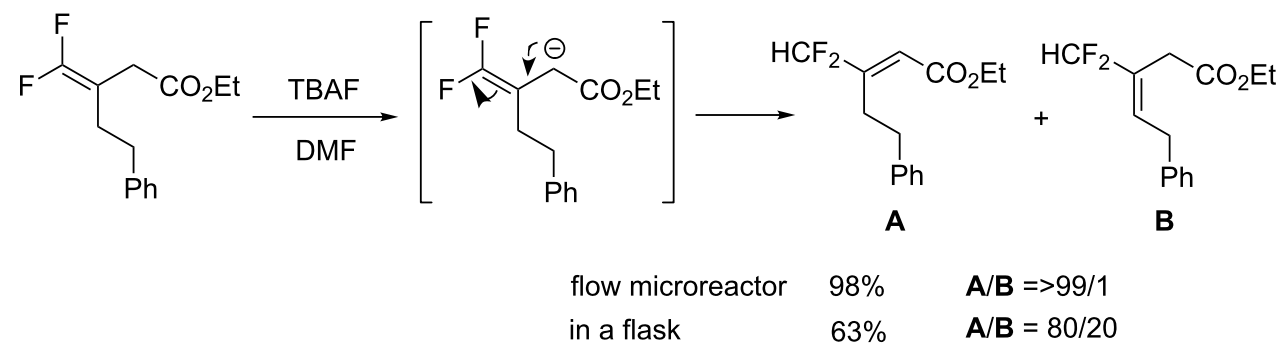


The Pd-catalyzed fluorination of aryl triflates with fluoride was developed by Buchwald and co-workers in 2009 [52]. Both electron-rich and -poor aryl triflates underwent Pd-catalyzed aromatic fluorination. As a fluoride source, they used CsF, which is an expensive reagent. They found that the use of a large excesses of CsF shortened reaction times for catalytic aromatic fluorination. Furthermore, efficient mixing becomes difficult when dealing with large quantities of insoluble CsF. They invented a packed-bed flow reactor, which allowed for easy handling of large quantities of insoluble $\mathrm{CsF}$ with efficient mixing (Scheme 5) [53].

As an alternative method for aromatic fluorination, Yoshida and Nagaki reported the reactions of aryllithiums with electrophilic fluorinating agents such as NFSI and $N$-fluorosultam (Scheme 6) [54]. The present flow microreactor method showed a high level of functional group compatibility; a wide repertoire of aryl fluorides possessing electron-withdrawing, electron- donating, and sterically hindered functional groups were obtained in good yields. This is an important feature of 'latestage fluorination methodology' for efficient drug screening.

$\left[{ }^{18} \mathrm{~F}\right]$ is a fluorine radioisotope which acts as an important source of positrons. In the medical imaging modality, $\left[{ }^{18} \mathrm{~F}\right] \mathrm{FDG}$ is radiopharmaceutically used for positron emission tomography (PET). However, due to the short radioactivity elimination half-life of $\left[{ }^{18} \mathrm{~F}\right]\left(t_{1 / 2}=110 \mathrm{~min}\right)$, protocols for rapid and selective synthesis of $\left[{ }^{18} \mathrm{~F}\right]$-labeled compounds have been required. In addition, on-site and on-demand chemical production of PET agents with automation and ease of in-line purification is suitable for hospital use. To date, continuous flow microreactor technology has shown potential for synthesis of $\left[{ }^{18} \mathrm{~F}\right]$-radiolabeled molecular imaging probes such as $\left[{ }^{18} \mathrm{~F}\right] \mathrm{FDG}$, $\left[{ }^{18} \mathrm{~F}\right]$ fallypride, $\left[{ }^{18} \mathrm{~F}\right]$ annexin, and so on, which were made by nucleophilic substitution reactions using $\left[{ }^{18} \mathrm{~F}\right]$-fluoride ion (Scheme 7) [55-67].
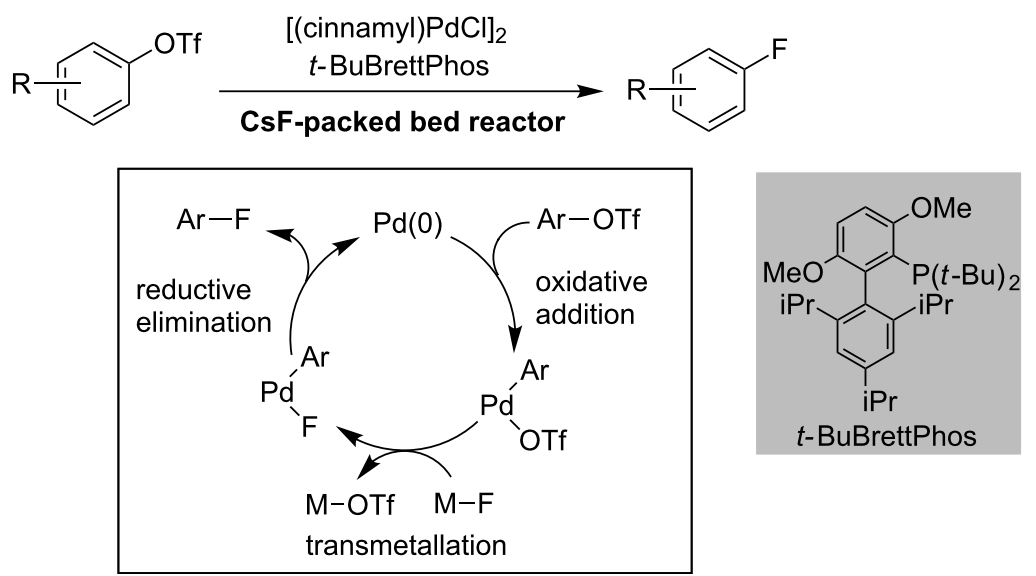

Scheme 5: Flow system for catalytic aromatic fluorination

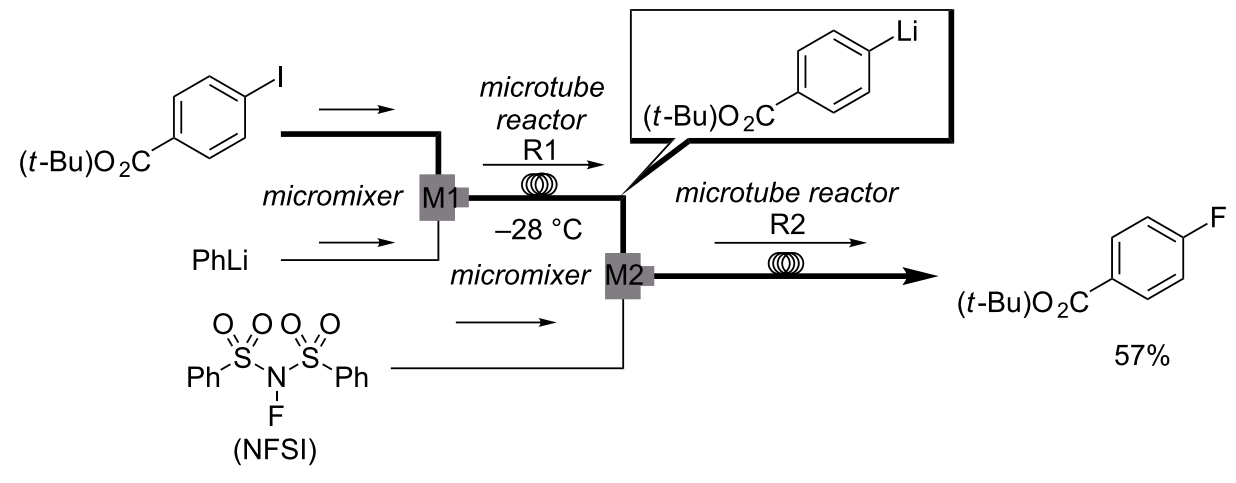




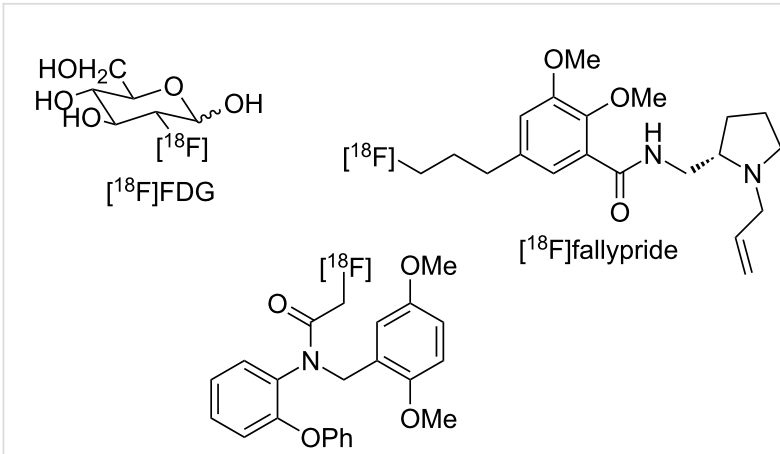

$N$-[ ${ }^{18}$ F]fluoroacetyl- $N$-(2,5-dimethoxybenzyl)-2-phenoxyaniline<smiles>COCC1=C(C(=O)OCC[Al])C(c2ccc(F)c(F)c2)N(C(=O)NCCCN2CCC(c3cccc(NC(C)=O)c3)CC2)C(=O)N1</smiles>

Scheme 7: Examples of $\left[{ }^{18} \mathrm{~F}\right]-$ radiolabeled molecular imaging probes.

For not only fluorination/fluoroalkylation, but also for defluorination, flow microreactor synthesis is quite effective. Defluorination involving a nucleophilic addition-elimination mechanism is a fundamental reaction in organic synthesis. Acid fluo- rides are known to be more stable to hydrolysis than acid chlorides under acidic or neutral conditions; on the other hand, they react with nucleophiles vigorously under basic conditions. Amino acid fluorides serve as one of the most efficient reagents for peptide bond formation. Seeberger and co-workers demonstrated the use of a silicon-based microreactor for the effective synthesis of peptides (Scheme 8) [68]. The condensation reaction completed in only $3 \mathrm{~min}$ at $90{ }^{\circ} \mathrm{C}$ to afford the dipeptide in high yield. Under the conditions at higher temperatures and/or leaving in prolonged contact with the reagents, decreasing the chemical yield of the desired dipeptide and increasing the amount of the tripeptide were observed. Using a flow microreactor system, precise residence-time control avoided the formation of undesired tripeptide byproduct.

Nucleophilic aromatic substitution $\left(\mathrm{S}_{\mathrm{N}} \mathrm{Ar}\right)$ chemistry contributes to creating useful materials. In 2005, Comer and Organ reported $\mathrm{S}_{\mathrm{N}} \mathrm{Ar}$ reactions of 2-fluoronitrobenzene using a flow microreactor system with microwave irradiation (Scheme 9) [69]. Toward making compound-libraries, Schwalbe explored a flow microreactor system for sequential transformation towards fluoroquinolone antibiotics such as ciprofloxacin via both inter- and intramolecular $\mathrm{S}_{\mathrm{N}} \mathrm{Ar}$ reactions (Scheme 10) [70]. Starting from the acylation reaction of ( $N$-dimethylamino)acrylate with 2,4,5-trifluorobenzoic acid chloride, followed by two kinds of library diversification involving 1 )

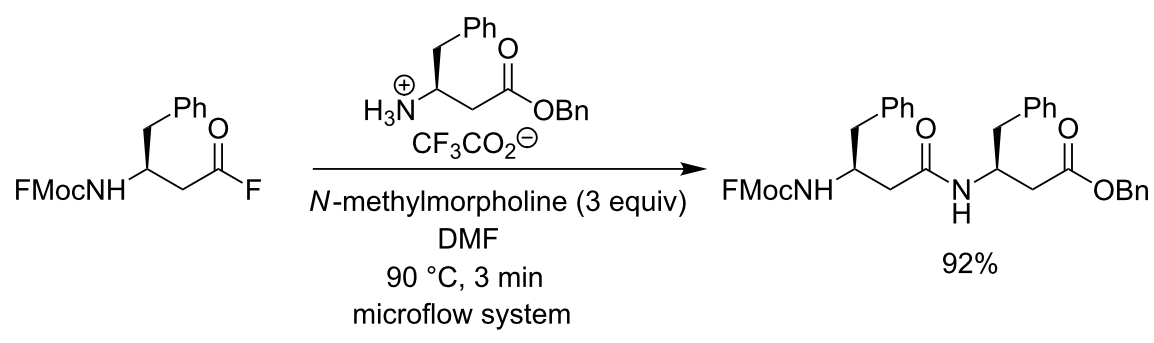

Scheme 8: Flow microreactor synthesis of dipeptides.

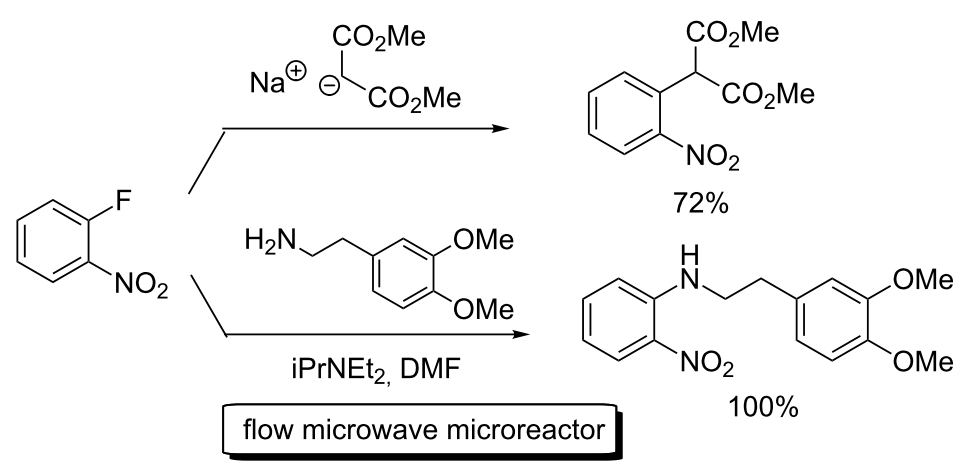

Scheme 9: Flow synthesis involving $S_{N} A r$ reactions. 


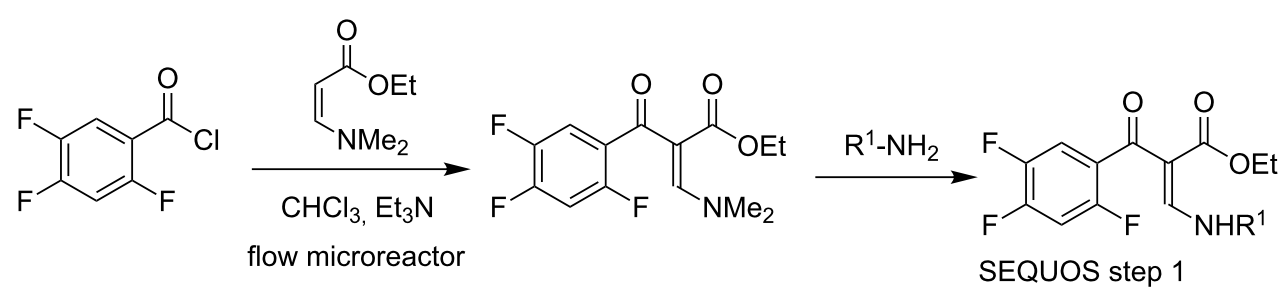<smiles>[R12]N[C@H](C)CCOC(=O)c1c[nH]c2cc(F)c(F)cc2c1=O</smiles><smiles>[R]Nc1cc2c(cc1F)c(=O)c(C(=O)OCC)cn2[R]</smiles>

carried out in collector SEQUOS step 2

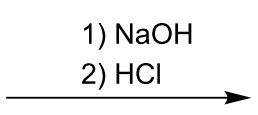

carried out in collector<smiles>[R]N([R])c1cc2c(cc1F)c(=O)c(C(=O)O)cn2[R]</smiles>

carried out in collector

(SEQUOS = sequential organic synthesis $)$

Scheme 10: Flow synthesis of fluoroquinolone antibiotics.

Michael addition of a set of primary amines and the subsequent nucleophilic ring closure to give the difluoroquinolone system, 2) intermolecular nucleophilic aromatic substitution with various amines and hydrolysis of ester moieties to afford a number of ciprofloxacin analogues in good overall yields with high purity.

\section{Reactions in which a reactive intermediate easily decomposes in batch reactors}

As aforementioned, the benefits of flow microreactor synthesis are 1) accurate control of reaction time, temperature, and pressure, 2) efficient mixing, 3) improved product selectivity (yield and purity), 4) rapid removal of heat of reaction for increased process safety, 5) ease of scale-up from lab to plant scale, and so on.

The reaction times are governed by the residence times (concerning path lengths and flow rates) inside flow microre- actor which allow the generation and reactions of reactive intermediates before decomposition. By virtue of these characteristic features, the residence time control in flow microreactors makes the generation of highly reactive species possible, including their reactions on a preparative scale within a second or less.

Pentafluorophenylmagnesium bromide $(\mathrm{PFPMgBr})$ is industrially produced by means of the halogen-metal exchange reaction of ethylmagnesium bromide and bromopentafluorobenzene [71]. However, this process is a highly exothermic reaction, and therefore, the use of a slow addition technique is required to avoid rapid increase in temperature. The flow reactor systems with micromixer and microheat exchangers show efficacy of forming PFPMgBr (Scheme 11) [72]. In the well-controlled formation of $\mathrm{PFPMgBr}$ and the subsequent protonation, continuous running of the pilot plant-scale flow microreactor gave pentafluorobenzene (PFB) in 92\% yield $(14.7 \mathrm{~kg})$.
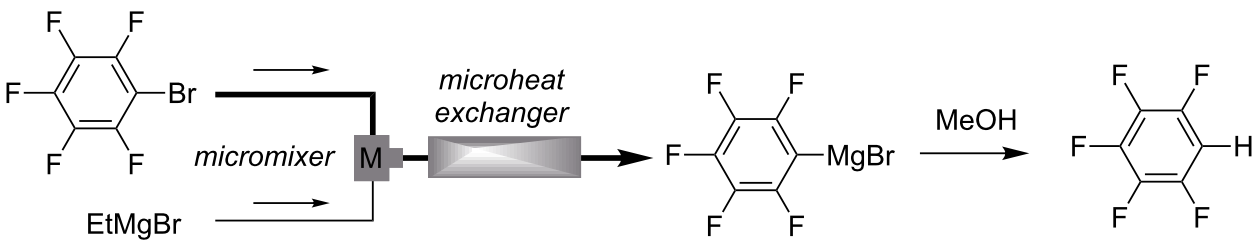
Molecular switches based on photochromic diarylethenes are one of the most promising electronic materials [73]. In particular, a number of 1,2-bis(heteroaryl)-substituted perfluorocyclopentenes have been synthesized for use as photosensitive components of photochromic recording media for optical memory. For the synthesis of 1,2-diarylperfluorocyclopentenes, octafluorocyclopentene undergoes very quick reaction with nucleophiles because of the extremely high electrophilicity of the double bond [74]. The nucleophilic substitutions take place in a stepwise manner via an addition-elimination pathway. However, it is difficult to synthesize unsymmetrical diarylethenes with conventional macro batch systems because of contamination of the symmetrical diarylethenes (two identical nucleophiles are incorporated at the same time). Integrated flow microreactor synthesis of photochromic diarylethenes was found to be effective; the generation of heteroaryllithiums and the subsequent nucleophilic addition/elimination with octafluorocyclopentene were successfully achieved (Scheme 12) [75] As a significant progress, the selective synthesis of unsymmetrical diarylethenes was accomplished by stepwise introduction of different heteroaryl nucleophiles into octafluorocyclopentene with highly controlled manner [76].

The installation of perfluoroalkyl moieties into organic molecules can substantially changes the electronic properties of the parent organic compounds, and improves lipophilicity leading to enhanced solubility in fatty tissue and more efficient transport in the body. Nucleophilic introduction of perfluoroalkyl $\left(\mathrm{R}_{\mathrm{F}}\right)$ groups are one of the most effective and general methods for the synthesis of perfluoroalkylated compounds [77] Perfluoroalkyllithiums, which are usually prepared by halogen-lithium exchange reactions of perfluoroalkyl halides with alkyllithiums are useful for nucleophilic perfluoroalkylation [78], however they readily undergo $\beta$-elimination to form perfluoroalkenes [79]. Flow microreactor systems were proved to be effective for generation and reactions of $\mathrm{R}_{\mathrm{F}} \mathrm{Li}$ avoiding the $\beta$-elimination [80]. In the case of benzaldehyde as an electrophile, the reactions could be conducted at $0{ }^{\circ} \mathrm{C}$, although much lower temperatures such as $-78^{\circ} \mathrm{C}$ are required to avoid the decomposition of perfluoroalkyllithium intermediates in batch processes (Scheme 13). However, the use of highly reactive electrophiles such as trimethylsilyl triflate and chlorotributylstannane gave rise to very low yields of the desired products, because the reactions of MeLi with such electrophiles are faster than those with perfluoroalkyl halides. In such cases, the generation of $\mathrm{R}_{\mathrm{F}} \mathrm{Li}$ and the reactions with electrophiles should be separated to give the desired $\mathrm{R}_{\mathrm{F}} \mathrm{SiMe}_{3}$ and $\mathrm{R}_{\mathrm{F}} \mathrm{SnBu}_{3}$ in high yields. To solve the issue, the use of the integrated flow microreactor system was effective; well-controlled generation of highly reactive $\mathrm{R}_{\mathrm{F}} \mathrm{Li}$ intermediates in the absence of active electrophiles and transfer of $\mathrm{R}_{\mathrm{F}} \mathrm{Li}$ into the next step were accomplished by taking short residence times in the reactors before they decomposed (Scheme 14).

\section{Conclusion}

The illustrious achievements have been made in developing organic reactions by the use of flow microreactor devices. Fluorinated organic compounds have been gaining a significant importance in wide field of science and technology, and there have been the associated growing need for new and more efficient synthetic methods. As highlighted here, each of these elegant flow microreactor syntheses surely supplies the innovative methods for the synthesis of organo-fluorine compounds. For the future, continuous flow microreactor chemistry will make a breakthrough in developing new chemical production with highly efficiency and unexploited fluorinated intermediates by the ingenious strategy, and will afford fluorinecontaining useful materials.

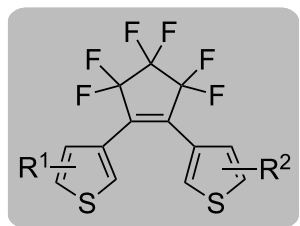

photochromic diarylethenes<smiles>FC1=C(F)C(F)(F)C(F)(F)C1(F)F</smiles>

F F

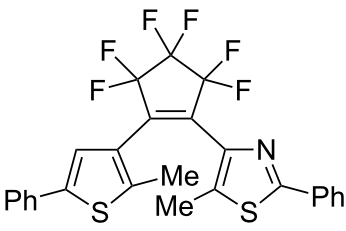

$94 \%$
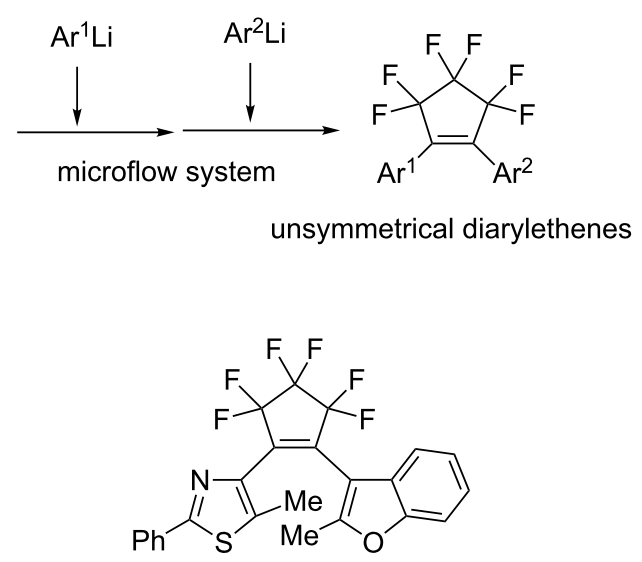

$82 \%$ 


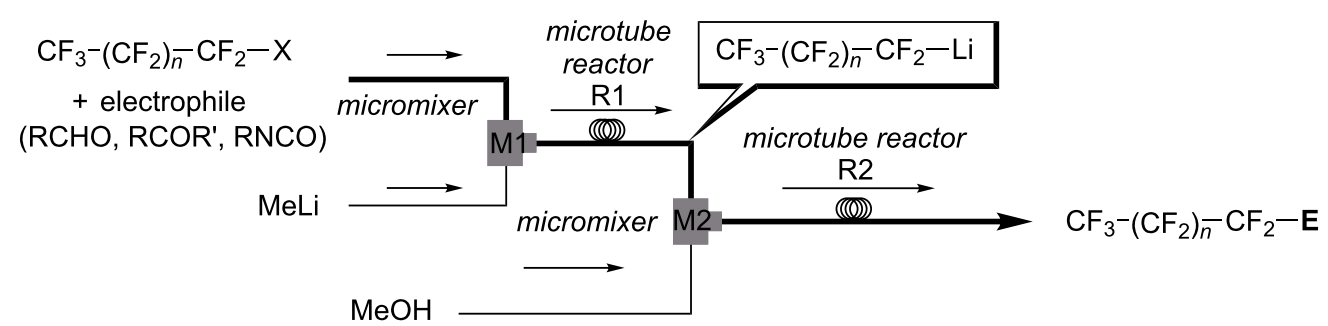

products:<smiles>OC(c1ccccc1)C(F)(F)C(F)(F)F</smiles>

$(84 \%)$<smiles>OC(c1ccccc1)C(F)(F)C(F)(F)F</smiles>

$(85 \%)$

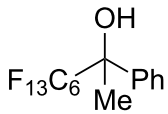

$(70 \%)$
$\mathrm{C}_{6} \mathrm{~F}_{13}-\mathrm{SiMe}_{3}$

$(30 \%)$
$\mathrm{C}_{6} \mathrm{~F}_{13}-\mathrm{SnBu}_{3}$

$(2 \%)$

Scheme 13: Flow microreactor system for perfluoroalkylation by generation of perfluoroalkyllithiums in the presence of electrophiles.

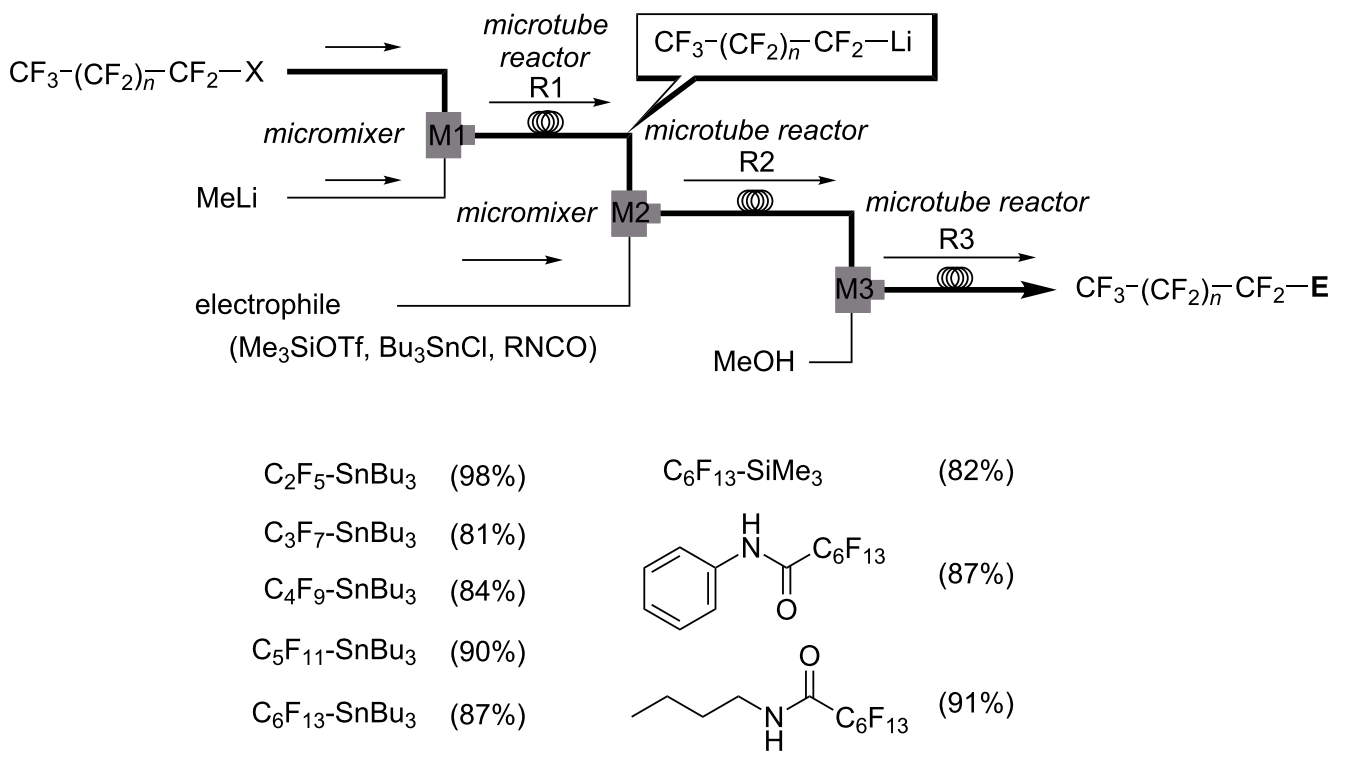

Scheme 14: Integrated flow microreactor system for perfluoroalkylation by generation of perfluoroalkyllithiums in the absence of electrophiles.

\section{Acknowledgements}

The financial support of the Ministry of Education, Culture, Sports, Science and Technology of Japan (Grant-in-Aid for Scientific Research on Innovative Areas "Organic Synthesis Based on Reaction Integration") is gratefully acknowledged.

\section{References}

1. Banks, R. E.; Smart, B. E.; Tatlow, J. C. Organofluorine Chemistry: Principles and Commercial Applications; Plenum Press: New York, 2000.

2. Hiyama, T.; Kanie, K.; Kusumoto, T.; Morizawa, Y.; Shimizu, M. Organofluorine Compounds: Chemistry and Application; Springer-Verlag: Berlin, 2000. doi:10.1007/978-3-662-04164-2

3. Kirsch, P. Modern Fluoroorganic Chemistry; Wiley-VCH: Weinheim, 2004. doi:10.1002/352760393X
4. Chambers, R. D. Fluorine in Organic Chemistry; Blackwell: Oxford, 2004. doi:10.1002/9781444305371

5. Uneyama, K. Organofluorine Chemistry; Blackwell: Oxford, 2006. doi:10.1002/9780470988589

6. Bégué, J.-P.; Bonnet-Delpon, D. Bioorganic and Medicinal Chemistry of Fluorine; John Wiley \& Sons, Inc.: Hoboken, NJ, 2008. doi:10.1002/9780470281895

7. Ojima, I. Fluorine in Medicinal Chemistry and Chemical Biology; Wiley-Blackwell: Chichester, West Sussex, 2009.

8. Gouverneur, V.; Müller, K., Eds. Fluorine in Pharmaceutical and Medicinal Chemistry: From Biophysical Aspects to Clinical Applications; World Scientific Publishing Company: London, 2012. doi:10.1142/p746

9. Thayer, A. M. Chem. Eng. News 2006, 84, 15-24.

10. Hagmann, W. K. J. Med. Chem. 2008, 51, 4359-4369. doi:10.1021/jm800219f 
11. Yoshida, J. Flash Chemistry: Fast Organic Synthesis in Microsystems; Wiley: Chichester, West Sussex, 2008.

12. Wiles, C.; Watts, P. Micro Reaction Technology in Organic Synthesis; CRC Press: Boca Raton, FL, 2011.

13. Wirth, T., Ed. Microreactors in Organic Chemistry and Catalysis; Wiley-VCH: Weinheim, 2013. doi:10.1002/9783527659722

14. Yoshida, J.; Nagaki, A.; Yamada, D. Drug Discovery Today 2013, 10 , e53-e59. doi:10.1016/j.ddtec.2012.10.013

15. Yoshida, J. Chem. Rec. 2010, 10, 332-341. doi:10.1002/tcr.201000020

16. McQuade, D. T.; Seeberger, P. H. J. Org. Chem. 2013, 78, 6384-6389. doi:10.1021/j0400583m

17. Schwalbe, T.; Simoms, K. Chim. Oggi 2006, 24, 56-61.

18. Suga, S.; Yamada, D.; Yoshida, J. Chem. Lett. 2010, 39, 404-406. doi:10.1246/cl.2010.404

19. Yoshida, J.; Saito, K.; Nokami, T.; Nagaki, A. Synlett 2011, 1189-1194. doi:10.1055/s-0030-1259946

20. Nagaki, A.; Kim, H.; Usutani, H.; Matsuo, C.; Yoshida, J. Org. Biomol. Chem. 2010, 8, 1212-1217. doi:10.1039/b919325c

21. Tomida, Y.; Nagaki, A.; Yoshida, J. J. Am. Chem. Soc. 2011, 133, 3744-3747. doi:10.1021/ja110898s

22. Nagaki, A.; Kim, H.; Yoshida, J. Angew. Chem., Int. Ed. 2008, 47, 7833-7836. doi:10.1002/anie.200803205

23. Usutani, H.; Tomida, Y.; Nagaki, A.; Okamoto, H.; Nokami, T.; Yoshida, J. J. Am. Chem. Soc. 2007, 129, 3046-3047. doi:10.1021/ja068330s

24. Kim, H.; Nagaki, A.; Yoshida, J. Nat. Commun. 2011, 2, No. 264. doi:10.1038/ncomms1264

25. Saito, K.; Ueoka, K.; Matsumoto, K.; Suga, S.; Nokami, T.; Yoshida, J. Angew. Chem., Int. Ed. 2011, 50, 5153-5156. doi:10.1002/anie.201100854

26. Chambers, R. D.; Spink, R. C. H. Chem. Commun. 1999, 883-884. doi:10.1039/a901473j

27. Chambers, R. D.; Greenhall, M. P.; Hutchinson, J. J. Chem. Soc., Chem. Commun. 1995, 21-22. doi:10.1039/C39950000021

28. Chambers, R. D.; Greenhall, M. P.; Hutchinson, J. Tetrahedron 1996, 52, 1-8. doi:10.1016/0040-4020(95)00883-A

29. Chambers, R. D.; Sandford, G. Chim. Oggi 2004, 22, 6-8.

30. Jähnisch, K.; Baerns, M.; Hessel, V.; Ehrfeld, W.; Haverkamp, V.; Löwe, H.; Wille, C.; Guber, A. J. Fluorine Chem. 2000, 105, 117-128. doi:10.1016/S0022-1139(00)00300-6

31. Chambers, R. D.; Holling, D.; Spink, R. C. H.; Sandford, G. Lab Chip 2001, 1, 132-137. doi:10.1039/b108841f

32. Löb, P.; Löwe, H.; Hessel, V. J. Fluorine Chem. 2004, 125, 1677-1694. doi:10.1016/j.jfluchem.2004.09.006

33. Chambers, R. D.; Fox, M. F.; Sandford, G. Lab Chip 2005, 5 , 1132-1139. doi:10.1039/b504675k

34. Sato, T. Preparation of fluorinated organic compounds by direct fluorination. Jpn. Kokai Tokkyo Koho JP 2006-001881, Jan 5, 2006.

35. de Mas, N.; Günther, A.; Schmidt, M. A.; Jensen, K. F. Ind. Eng. Chem. Res. 2009, 48, 1428-1434. doi:10.1021/ie801232d

36. Chambers, R. D.; Fox, M. A.; Sandford, G.; Trmcic, J.; Goeta, A. J. Fluorine Chem. 2007, 128, 29-33. doi:10.1016/j.jluchem.2006.09.010

37. Hessel, V.; Angeli, P.; Gavriilidis, A.; Löwe, H. Ind. Eng. Chem. Res. 2005, 44, 9750-9769. doi:10.1021/ie0503139 And references therein.

38. Grakauskas, V. J. Org. Chem. 1969, 34, 2835-2839. doi:10.1021/jo01262a009
39. Cacace, F.; Giacomello, P.; Wolf, A. P. J. Am. Chem. Soc. 1980, 102, 3511-3515. doi:10.1021/ja00530a034

40. Purrington, S. T.; Woodard, D. L. J. Org. Chem. 1991, 56, 142-145. doi:10.1021/jo00001a029

41. Messina, P. A.; Mange, K. C.; Middleton, W. J. J. Fluorine Chem. 1989, 42, 137-143. doi:10.1016/S0022-1139(00)83974-3

42. von Allenstein, E.; Schrempf, G. Z. Anorg. Allg. Chem. 1981, 474, 7-17.

43. Lal, G. S.; Pez, G. P.; Pesaresi, R. J.; Prozonic, F. M.; Cheng, H. J. Org. Chem. 1999, 64, 7048-7054. doi:10.1021/jo990566+

44. Gustafsson, T.; Gilmour, R.; Seeberger, P. H. Chem. Commun. 2008, 3022-3024. doi:10.1039/b803695k

45. Baumann, M.; Baxendale, I. R.; Ley, S. V. Synlett 2008, 2111-2114. doi:10.1055/s-2008-1078026

46. Baumann, M.; Baxendale, I. R.; Martin, L. J.; Ley, S. V. Tetrahedron 2009, 65, 6611-6625. doi:10.1016/j.tet.2009.05.083

47. Carter, C. F.; Lange, H.; Ley, S. V.; Baxendale, I. R.; Wittkamp, B.; Goode, J. G.; Gaunt, N. L. Org. Process Res. Dev. 2010, 14, 393-404. doi:10.1021/op900305v

48. Torres, J. C.; Garden, S. J.; Pinto, A. C.; da Silva, F. S. Q.; Boechat, N. Tetrahedron 1999, 55, 1881-1892. doi:10.1016/S0040-4020(98)01229-0

49. Li, G.; van der Donk, W. A. Org. Lett. 2007, 9, 41-44. doi:10.1021/ol062401a

50. Taguchi, M.; Nakaya, H.; Ichihara, K.; Senba, Y.; Hiraga, Y. Manufacture of fluorine-containing epoxides from fluoroalkyl iodides and unsaturated alcohols. Jpn. Kokai Tokkyo Koho JP 2009-67687, April 2, 2009.

51. Kitazume, T.; Kawai, K.; Nihei, T.; Miyake, N. J. Fluorine Chem. 2005, 126, 59-62. doi:10.1016/j.jfluchem.2004.10.008

52. Watson, D. A.; Su, M.; Teverovskiy, G.; Zhang, Y.; Garcia-Fortanet, J.; Kinzel, T.; Buchwald, S. L. Science 2009, 325, 1661-1664. doi:10.1126/science.1178239

53. Noël, T.; Maimone, T. J.; Buchwald, S. L. Angew. Chem., Int. Ed. 2011, 50, 8900-8903. doi:10.1002/anie.201104652

54. Nagaki, A.; Uesugi, Y.; Kim, H.; Yoshida, J. Chem.-Asian J. 2013, 8, 705-708. doi:10.1002/asia.201201191

55. Lee, C.-C.; Sui, G.; Elizarov, A.; Shu, C. J.; Shin, Y.-S.; Dooley, A. N.; Huang, J.; Daridon, A.; Wyatt, P.; Stout, D.; Kolb, H. C.; Witte, O. N.; Satyamurthy, N.; Heath, J. R.; Phelps, M. E.; Quake, S. R.; Tseng, H.-R. Science 2005, 310, 1793-1796 doi:10.1126/science.1118919

56. Elizarov, A. M.; van Dam, R. M.; Shin, Y. S.; Kolb, H. C.; Padgett, H. C.; Stout, D.; Shu, J.; Huang, J.; Daridon, A.; Heath, J. R. J. Nucl. Med. 2010, 51, 282-287. doi:10.2967/jnumed.109.065946

57. Gillies, J. M.; Prenant, C.; Chimon, G. N.; Smethurst, G. J.; Dekker, B. A.; Zweit, J. Appl. Radiat. Isot. 2006, 64, 333-336. doi:10.1016/j.apradiso.2005.08.009

58. Steel, C. J.; O’Brien, A. T.; Luthra, S. K.; Brady, F. J. Labelled Compd. Radiopharm. 2007, 50, 308-311. doi:10.1002/jlcr.1259

59. Gillies, J. M.; Prenant, C.; Chimon, G. N.; Smethurst, G. J.; Perrie, W.; Hamblett, I.; Dekker, B.; Zweit, J. Appl. Radiat. Isot. 2006, 64, 325-332. doi:10.1016/j.apradiso.2005.08.007

60. Lu, S.; Giamis, A. M.; Pike, V. W. Curr. Radiopharm. 2009, 2, 49-55. doi:10.2174/1874471010902010049

61. Briard, E.; Zoghbi, S. S.; Siméon, F. G.; Imaizumi, M.; Gourley, J. P.; Shetty, H. U.; Lu, S.; Fujita, M.; Innis, R. B.; Pike, V. W. J. Med. Chem. 2009, 52, 688-699. doi:10.1021/jm8011855 
62. Lu, S.-Y.; Watts, P.; Chin, F. T.; Hong, J.; Musachio, J. L.; Briard, E.; Pike, V. W. Lab Chip 2004, 4, 523-525. doi:10.1039/b407938h

63. Pascali, G.; Mazzone, G.; Saccomanni, G.; Manera, C.; Salvadori, P. A. Nucl. Med. Biol. 2010, 37, 547-555. doi:10.1016/j.nucmedbio.2010.03.006

64. Pascali, G.; Nannavecchia, G.; Pitzianti, S.; Salvadori, P. A. Nucl. Med. Biol. 2011, 38, 637-644. doi:10.1016/j.nucmedbio.2011.01.005

65. Chun, J.-H.; Lu, S.; Lee, Y.-S.; Pike, V. W. J. Org. Chem. 2010, 75, 3332-3338. doi:10.1021/jo100361d

66. Philippe, C.; Ungersboeck, J.; Schirmer, E.; Zdravkovic, M.; Nics, L.; Zeilinger, M.; Shanab, K.; Lanzenberger, R.; Karanikas, G.; Spreitzer, H.; Viernstein, H.; Mitterhauser, M.; Wadsak, W. Bioorg. Med. Chem. 2012, 20, 5936-5940. doi:10.1016/j.bmc.2012.07.051

67. Keng, P. Y.; Chen, S.; Ding, H.; Sadeghi, S.; Shah, G. J.; Dooraghi, A.; Phelps, M. E.; Satyamurthy, N.; Chatziioannou, A. F.; Kim, C.-J.; van Dam, R. M. Proc. Natl. Acad. Sci. U. S. A. 2012, 109, 690-695. doi:10.1073/pnas.1117566109

68. Flögel, O.; Codée, J. D. C.; Seebach, D.; Seeberger, P. H. Angew. Chem., Int. Ed. 2006, 45, 7000-7003. doi:10.1002/anie.200602167

69. Comer, E.; Organ, M. G. J. Am. Chem. Soc. 2005, 127, 8160-8167. doi:10.1021/ja0512069

70. Schwalbe, T.; Kadzimirsz, D.; Jas, G. QSAR Comb. Sci. 2005, 24, 758-768. doi:10.1002/qsar.200540005

71. Respess, W. L.; Tamborski, C. J. Organomet. Chem. 1968, 11, 619-622. doi:10.1016/0022-328X(68)80092-0

72. Wakami, H.; Yoshida, J. Org. Process Res. Dev. 2005, 9, 787-791. doi:10.1021/op0501500

73. Irie, M. Chem. Rev. 2000, 100, 1685-1716. doi:10.1021/cr980069d

74. Amii, H.; Uneyama, K. Chem. Rev. 2009, 109, 2119-2183. doi:10.1021/cr800388c

75. Ushiogi, Y.; Hase, T.; linuma, Y.; Takata, A.; Yoshida, J. Chem. Commun. 2007, 2947-2949. doi:10.1039/b702277h

76. Asai, T.; Takata, A.; Nagaki, A.; Yoshida, J. ChemSusChem 2012, 5, 339-350. doi:10.1002/cssc.201100376

77. Schwalbe, T.; Autze, V.; Hohmann, M.; Stirner, W. Org. Process Res. Dev. 2004, 8, 440-454. doi:10.1021/op049970n See for a Grignard exchange reaction of $\mathrm{C}_{2} \mathrm{~F}_{5}$ I with $\mathrm{MeMgCl}$ followed by reaction with benzophenone in a microflow system.

78. Uno, H.; Suzuki, H. Synlett 1993, 91-96. doi:10.1055/s-1993-22361

79. Uneyama, K.; Katagiri, T.; Amii, H. Acc. Chem. Res. 2008, 41, 817-829. doi:10.1021/ar7002573

80. Nagaki, A.; Tokuoka, S.; Yamada, S.; Tomida, Y.; Oshiro, K.; Amii, H.; Yoshida, J. Org. Biomol. Chem. 2011, 9, 7559-7563. doi:10.1039/c1ob06350b

\section{License and Terms}

This is an Open Access article under the terms of the Creative Commons Attribution License

(http://creativecommons.org/licenses/by/2.0), which permits unrestricted use, distribution, and reproduction in any medium, provided the original work is properly cited.

The license is subject to the Beilstein Journal of Organic Chemistry terms and conditions:

(http://www.beilstein-journals.org/bjoc)

The definitive version of this article is the electronic one which can be found at:

doi:10.3762/bjoc. 9.314 